\title{
The Use of Cryogenic Temperature Gas Chromatography for the Determination of Carbon Monoxide and Carbon Dioxide in Cigarette Smoke*
}

\author{
by Gerald P. Morie and Cephas H. Sloan \\ Research Laboratories, Tennessee Eastman Company, Division of Eastman Kodak Company, \\ Kingsport, Tennessee, USA
}

\section{INTRODUCTION}

The fact that cigarette smoke contains carbon monoxide and carbon dioxide is well known. Over the past fifty years, a number of workers have used colorimetry, titrimetry, infrared spectroscopy, mass spectrometry, and gas chromatography to determine these two compounds in cigarette smoke. The amounts of these compounds reported and the methods employed were well summarized by Elmenhorst and Schultz in 1968 (1).

Usually, $\mathrm{CO}$ and $\mathrm{CO}_{2}$ must be determined separately regardless of the method employed. Probably the most frequently used method for the determination of $\mathrm{CO}$ is gas chromatographic separation on a molecular sieve column (2). This approach was used by Mumpower et al. for the determination of $\mathrm{CO}$ in cigarette smoke in 1962 (3). (In this method $\mathrm{CO}_{2}$ is not determined, and the column must be protected from water and organic vapors in the smoke.) Most chromatographic methods for the simultaneous determination of $\mathrm{CO}$ and $\mathrm{CO}_{2}$ employ a combination of columns. A combination of an activated charcoal column and molecular sieve column as well as a combination of a silica gel column and a molecular sieve column (2) has been used for this purpose (4).

In this paper, a gas chromatographic method for the determination of $\mathrm{CO}$ and $\mathrm{CO}_{2}$ mixtures is described. The separation of $\mathrm{N}_{2}, \mathrm{O}_{2}, \mathrm{CO}$, and $\mathrm{CO}_{2}$ was achieved at temperatures of $-70^{\circ} \mathrm{C}$ to $+40^{\circ} \mathrm{C}$ on a single column containing Porapak $Q$ packing. Water and organic compounds are not detrimental to the column; in fact, the determination of $\mathrm{CO}$ and $\mathrm{CO}_{2}$ and the analysis of the organic vapor phase in cigarette smoke may be performed on a single sample by temperature programming from $\rightarrow 0^{\circ} \mathrm{C}$ to $+220^{\circ} \mathrm{C}$.

\section{EXPERIMENTAL}

\section{Apparatus}

A Beckman Model GC-5 gas chromatograph equipped with both flame ionization and thermal conductivity detectors was used in this work. A Beckman Model
125455 low-temperature accessory was installed on the chromatograph. This accessory employs a solenoid valve which, when actuated, passes a controlled flow of liquid $\mathrm{CO}_{2}$ through an orifice into the column compartment. The device is claimed to extend the lower temperature limit of the chromatograph downward to $-65^{\circ} \mathrm{C}$. However, the time required to achieve this temperature was unreasonably long, and temperature control was unsatisfactory. Therefore, the device was modified for use with liquid $\mathrm{N}_{2}$, and the size of the orifice was increased. A I5-1, liquid $\mathrm{N}_{2}$ container equipped with a discharge manifold (Sulfrain Cryogenics, Inc., Rahway, N. J.) was connected to the low-temperature accessory. After these modifications were completed, the chromatographic oven could be cooled to $-70^{\circ} \mathrm{C}$ in approximately $7 \mathrm{~min}$.

The chromatograph was equipped with a thermocouple which could be switched directly to the chromatographic recorder. This temperature measuring system was used to determine when the desired subambient temperature was reached.

A Finnigan Model $1015 \mathrm{~S} / \mathrm{L}$ gas chromatograph-mass spectrometer was used to identify components in the organic vapor phase of smoke.

A single-port smoking machine of our design was used to smoke cigarettes. The total particulate matter of the smoke was trapped on a Cambridge filter. A sample chamber for the gas phase of smoke was constructed from a $0.5-1$ Hamilton Model S-0550 syringe and two Hamilton Model 86406 three-way valves (Figure 1). As each puff was taken, the gas phase was transferred to the $0.5-1$ syringe before an aliquot of the gas phase was injected into the chromatographic column.

Figure 1. Gas-phase sample chamber and delivery system.

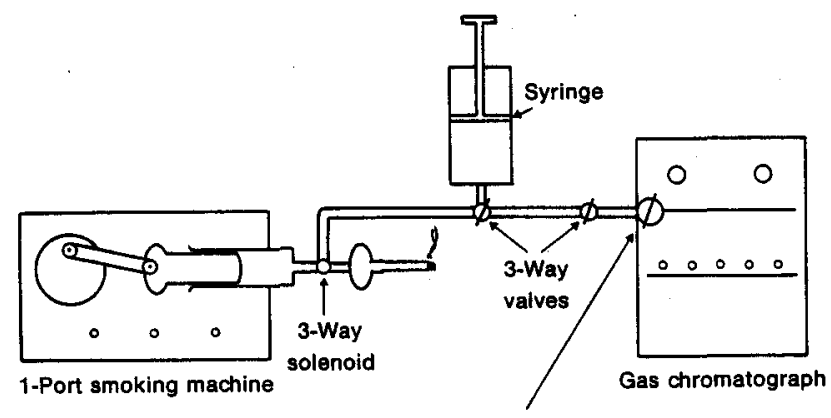

Gas-sampling valve 


\section{Procedure}

Cigarettes were smoked on the one-port smoking machine under standard conditions (one 2-sec. 35-ml puff per min.). During the smoking, liquid $\mathrm{N}_{2}$ was transferred into the chromatographic oven until the temperature was maintained at $-70^{\circ} \mathrm{C}$. The gas phase of the smoke which was in the $0.5-1$ syringe was slowly forced through the gas-sampling valve of the gas chromatograph. When approximately $100 \mathrm{ml}$ of sample had passed through the valve, a $2-\mathrm{ml}$ sample was injected onto the chromatographic column. The following chromatographic conditions were used:

A 1/8-in. $\times 12$-ft. SS column packed with Porapak $Q$ packing was programmed at $10^{\circ} / \mathrm{min}$. from $-70^{\circ} \mathrm{C}$ to $40^{\circ} \mathrm{C}$ for $\mathrm{N}_{2}, \mathrm{O}_{2}, \mathrm{CO}, \mathrm{CO}_{2}$ and to $220^{\circ} \mathrm{C}$ for the organic vapor phase; helium flow was $30 \mathrm{ml} / \mathrm{min}$.

An effluent splitter was used to split the sample at the detector so that $\mathrm{N}_{2}, \mathrm{O}_{2}, \mathrm{CO}$, and $\mathrm{CO}_{2}$ were detected with the thermal conductivity detector while the remaining peaks were detected with a flame ionization detector. The temperature of the column was maintained at $-70^{\circ} \mathrm{C}$ for $6 \mathrm{~min}$. as the $\mathrm{N}_{2}, \mathrm{O}_{2}$, and $\mathrm{CO}$ were eluted from the column. After the elution of $\mathrm{CO}$, one of three alternative procedures was selected: [1] When only $\mathrm{CO}$ was determined in a smoke sample, the column temperature was maintained at $-70^{\circ} \mathrm{C}$, and another smoke sample was injected onto the column as soon as the recorder pen returned to the baseline. [2] The column temperature was programmed at $10 \% \mathrm{~min}$. as soon as $\mathrm{CO}$ was eluted, and $\mathrm{CO}_{2}$ was detected in about $15 \mathrm{~min}$. After the elution of $\mathrm{CO}_{2}$, the column was either cooled to $-70^{\circ} \mathrm{C}$ in preparation for another sample, or [3] temperature programming of the column was continued for the analysis of the organic vapor phase. When the organic vapor phase was analyzed, the detector selector was switched from thermal conductivity to flame ionization, and temperature programming was continued until the column reached $220^{\circ} \mathrm{C}$. The organic vapor phase was then analyzed from the peaks in the remainder of the chromatogram.

\section{Calibration Curves}

A calibration for $\mathrm{CO}$ and $\mathrm{CO}_{2}$ was made as follows: Samples of 10 and $20 \mathrm{ml}$ of $\mathrm{CO}$ and $\mathrm{CO}_{2}$, respectively, were taken with a 50-ml gas-tight syringe at $25^{\circ} \mathrm{C}$. These samples were injected into the $0.5-1$ syringe described previously. Known volumes of $\mathrm{N}_{2}$ were then added to the large syringe resulting in known gas mixtures which contained from $2.38 \%$ to $7.5 \% \mathrm{CO}$ and from $5.0 \%$ to $14.5 \% \mathrm{CO}_{2}$. A 2-ml sample of each

Flgure 2. Gas chromatographic separation of $\mathrm{N}_{2}, \mathrm{O}_{2}, \mathrm{CO}, \mathrm{CO}_{2}$, and organic gas-phase components in clgarette smoke.
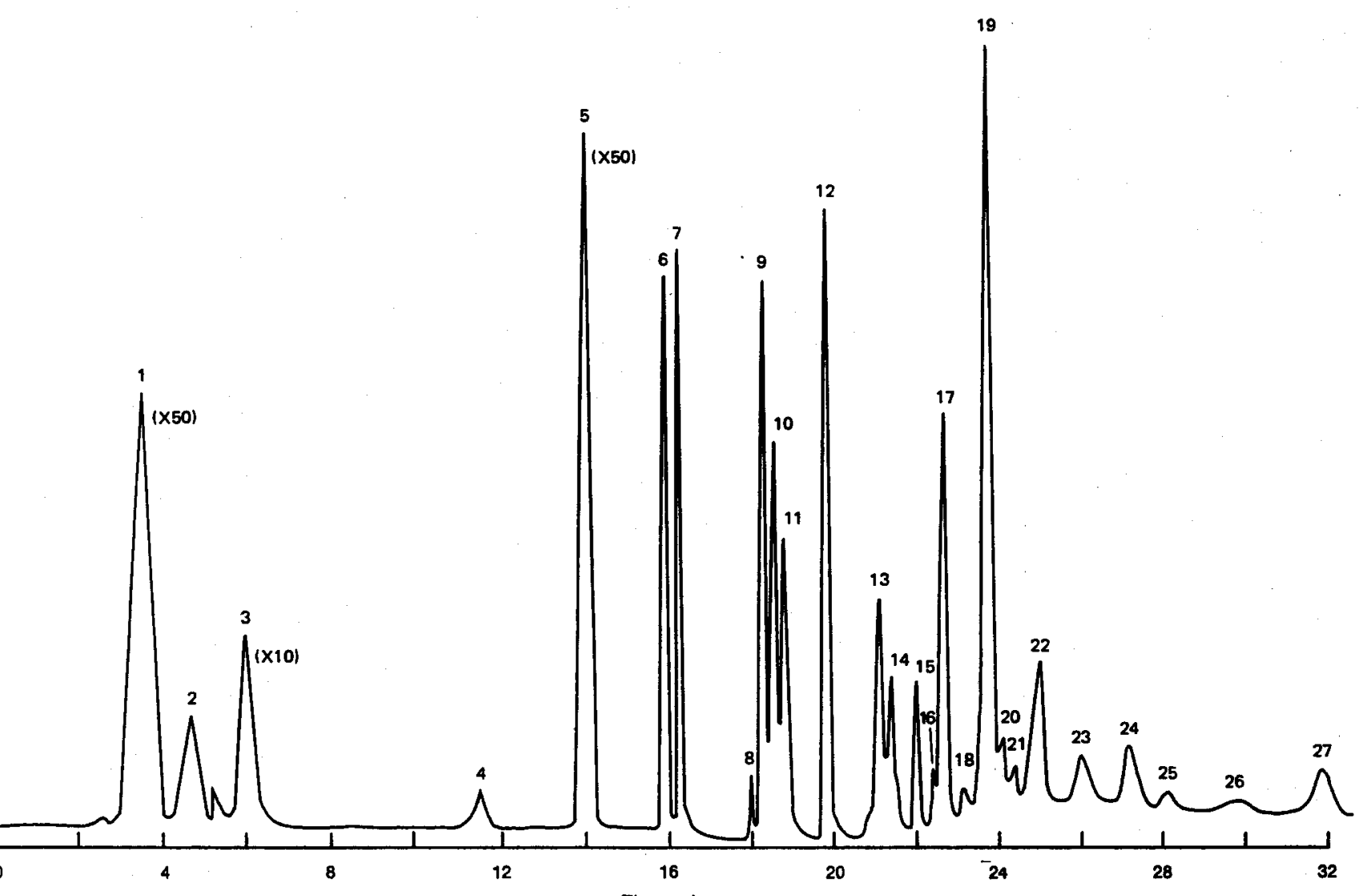

1. $\mathrm{N}_{2}$

2. $\mathrm{O}_{2}$

3. $\mathrm{CO}$

4. NO

5. $\mathrm{CO}_{2}$

6. ethylene

7. ethane
8. cyanogen, carbonylsulfide, and hydrogen cyanide

9. propylene

10. propane and chloromethane

11. methanol

12. acetaldehyde

13. butene and butadiene

14. butane and ethanol
15. acetonitrile

16. acrolein

17. furan and acetone

18. acrylonitrile

19. isoprene and pentene

20. pentadiene

21. unidentified
22. pentane

23. heptane and hexane

24. benzene

25. dimethylfuran

26. pyridine

27. toluene 
of these mixtures was introduced onto the chromatographic column by means of the gas sampling valve. Calibration curves, based on areas of the peaks versus volume percent, were constructed. Calibration curves for selected organic vapor phase components were constructed in a similar manner.

\section{RESULTS AND DISCUSSION}

A chromatogram of the separation is shown in Figure 2. The peaks for $\mathrm{N}_{2}, \mathrm{O}_{2}$, and $\mathrm{CO}$ are well resolved at $-70^{\circ} \mathrm{C}$. The next peak, which appeared as the temperature was programmed, had the same retention time as nitric oxide. Obviously, this small peak could not be used for the quantitative determination of NO in the smoke of an entire cigarette because of the oxidation of $\mathrm{NO}$ to $\mathrm{NO}_{2}$ in the presence of oxygen. Moreover, attempts to rapidly sample a single puff and quantitatively determine NO were unsuccessful. There was probably some adsorption of NO on the packing or some oxidation of NO during the chromatographic separation. Shortly after the $\mathrm{CO}_{2}$ was eluted from the Porapak $Q$ column, the organic vapor phase was separated into about 24 peaks, a rather small fraction of the several hundred vapor-phase components present in cigarette smoke ( 1 ). However, the separation was satisfactory for the routine evaluation of organic vaporphase adsorbents for cigarette filters.

The precision of the method was determined by measuring the areas of the $\mathrm{CO}$ and $\mathrm{CO}_{2}$ peaks on a series of 10 cigarettes. The coefficient of variation, including variations in cigarettes, was $4.6 \%$ and $5.8 \%$ for $\mathrm{CO}$ and $\mathrm{CO}_{2}$, respectively. The use of peak heights resulted in less precise measurements, probably because subambient temperature programming is not as reproducible as normal temperature programming.

Table 1. Carbon monoxide and carbon dloxide content of smoke from various clgarettes.

\begin{tabular}{l|l|c|c}
\hline Brand & Type of cigarette* & $\begin{array}{l}\text { CO } \\
\%\end{array}$ & $\begin{array}{c}\mathrm{CO}_{2} \\
\%\end{array}$ \\
\hline A & Nonfilter & 4.80 & 11.62 \\
B & Acetate filter & 4.65 & 11.05 \\
C & Acetate filter & 4.35 & 10.85 \\
D & Acetate carbon filter & 4.75 & 10.53 \\
E & Vented acetate filter & 2.85 & 8.32 \\
\hline
\end{tabular}

- Clgarettes tested were $85 \mathrm{~mm}$ in length.

The method was used to determine $\mathrm{CO}$ and $\mathrm{CO}_{2}$ in the gas phase of smoke from several domestic cigarettes. The percentage of $\mathrm{CO}$ and $\mathrm{CO}_{2}$ by volume is given for each of five brands in Table 1 . In general, the values agree with those reported previously $(1,4)$.

The amounts of $\mathrm{CO}$ and $\mathrm{CO}_{2}$ in the smoke of a cigarette. equipped with a vented filter have not been reported. The amount of air which enters the smoke through the vents of this filter was measured. An average value of $22 \%$ dilution of the smoke by air was obtained. However, the smoke from this cigarette contained $40 \%$
Table 2. Carbon monoxide and carbon dloxide content in smoke.

\begin{tabular}{c|c|c|c|r}
\hline \multirow{2}{*}{$\begin{array}{c}\text { Puff } \\
\text { number }\end{array}$} & \multicolumn{2}{|c|}{ Brand B } & \multicolumn{3}{|c}{ Brand C } \\
& \multicolumn{1}{c}{$\mathrm{Co}_{0}$} & \multicolumn{2}{c}{$\mathrm{CO}_{2}$} & \multicolumn{2}{c}{$\mathrm{Co}$} & \multicolumn{1}{c}{$\mathrm{CO}_{2}$} \\
\hline 2 & 4.10 & 9.65 & 3.95 & 9.52 \\
\hline 5 & 4.60 & 11.00 & 4.30 & 10.75 \\
8 & 5.03 & 13.30 & 4.82 & 12.97 \\
\hline
\end{tabular}

less $\mathrm{CO}$ than the smoke from cigarettes equipped with conventional filters. Apparently, the smaller puff volume ( $27 \mathrm{ml}$ in $2 \mathrm{sec}$.) contributes to this unexpected decrease of $\mathrm{CO}$ in cigarettes with vented filters.

The increase in $\mathrm{CO}$ and $\mathrm{CO}_{2}$ content of cigarette smoke as the cigarette is smoked has been reported by several investigators $(3,4)$. It is not the purpose of this paper to study this phenomenon in detail, but a few determinations were performed on single puffs of smoke to show the utility of the sampling device and the method. The results of these determinations (Table 2) are in agreement with those reported previously (3), and particularly agree with the recent data of Williams and Belk (4).

\section{SUMMARY}

A gas dhromatographic method for the determination of carbon monoxide and carbon dioxide in cigarette smoke was developed. A column containing Porapak $Q$ packing and a cryogenic temperature programmer which employed liquid nitrogen to cool the column to subambient temperatures was used. The separation of $\mathrm{N}_{2}, \mathrm{O}_{2}, \mathrm{CO}$, and $\mathrm{CO}_{2}$ was accomplished at temperatures of $-70^{\circ} \mathrm{C}$ to $40^{\circ} \mathrm{C}$, and the organic vapor phase of smoke was analyzed as the column temperature was programmed to $220^{\circ} \mathrm{C}$. The inorganic gases were detected by thermal conductivity and the organic vapors by flame ionization. The method was used to determine the amounts of carbon monoxide and carbon dioxide in the smoke of nonfilter, filter, and vented-filter cigarettes, and to analyze the organic vapor phase of smoke.

\section{ZUSAMMENFASSUNG}

Die Autoren entwickelten eine gaschromatographische Methode für die Bestimmung von Kohlenmonoxid und Kohlendioxid in Cigarettenrauch. Dazu werden eine mit Porapak $Q$ gepackte Säule sowie ein Kryostat mit Temperaturprogramm verwendet, der zur Kühlung der Säule flüssigen Stickstoff enthält. Die Trennung von $\mathrm{N}_{2}, \mathrm{O}_{2}, \mathrm{CO}$ und $\mathrm{CO}_{2}$ erfolgt bei Temperaturen zwischen $-70^{\circ}$ und $40^{\circ} \mathrm{C}$. Die organischen Bestandteile der Gasphase werden bei einer (programmierten) Säulentemperatur von $220^{\circ} \mathrm{C}$ durch Flammen-Ionisation, die anorganischen Bestandteile mit einem Wärmeleitfähigkeitsdetektor nachgewiesen. Mit Hilfe der beschriebenen Methode wurden der Gehalt an Kohlenmonoxid 
und Kohlendioxid im Rauch von filterlosen Cigaretten und von Filtercigaretten mit und ohne Perforation des Filters bestimmt und die organische Gasphase des Rauches untersucht.

\section{RESUME}

On a mis une méthode de chromatographie en phase gazeuse au point pour la détermination du monoxide et du dioxide de carbone dans la fumée de cigarettes. On a employé une colonne contenant du Porapak $Q$ et un programmateur de température cryogénique, qui utilise du nitrogène liquide pour refroidir la colonne au dessous de la température ambiante. On a réalisé l'isolation du $\mathrm{N}_{2}, \mathrm{O}_{2}, \mathrm{CO}$, et $\mathrm{CO}_{2}$ à des températures variant de $-70^{\circ} \mathrm{C}$ à $40^{\circ} \mathrm{C}$, et on a analysé la phase vapeur organique de la fumée à une température de colonne programmée à $220^{\circ} \mathrm{C}$. On a détecté les gaz inorganiques par conductivité thermique et les vapeurs organiques par ionisation de flamme. On a utilisé la méthode afin de déterminer les quantités de monoxide et de dioxide de carbone dans la fumée de cigarettes sans filtre, avec filtre et avec filtre aéré, et aussi pour l'analyse de la phase gazeuse organique de la fumée.

\section{REFERENCES}

1. Elmenhorst, H., and Schultz, C.: Beitr. Tabakforsch. $4(1.968) 90$.

2. Juvet, R. S., and Zadlo, F.: in "Advances in Chromatography", Vol. 2, J. C. Giddings and R. A. Keller, editors, Marcel Dekker, Inc., New York, 1965, pp. 265-271.

3. Mumpower, R. C., Lewis, J. S., and Touey, G. P.: Tob. Sci. $6(1962) 140$.

4. Williams, T. B., and Belk, C. W.: 24th Tobacco Chemists' Researdh Conference, Montreal, Canada, Oct. 28, 1970 .

\section{Acknowledgement}

The authors gratefully acknowledge the identification work by Mrs. Mary L. Simmons and Mr. J. S. Lewis, and the technical assistance of Mr. Michael Palmer.

The authors' address:

Tennessee Eastman Company, Research Laboratories, Kingsport, Tennessee, 37662; USA. 